IMECE2014-37348

\title{
INFLUENCE OF HARD TURNING ON MICROSTRUCTURE EVOLUTION IN THE SUBSURFACE LAYERS OF INCONEL 718
}

\author{
H. Touazine \\ Département de Génie Mécanique, \\ École de Technologie Supérieure \\ Montréal, Québec, Canada \\ heithem.touazine.1@ens.etsmtl.ca
}

\author{
M. Jahazi \\ Département de Génie Mécanique, \\ École de Technologie Supérieure \\ Montréal, Québec, Canada \\ mohammad.jahazi@etsmtl.ca
}

\author{
P. Bocher \\ Département de Génie Mécanique, \\ Ecole de Technologie Supérieure \\ Montréal, Québec, Canada \\ philippe.bocher@etsmtl.ca
}

\begin{abstract}
This study investigated the effects of semi finish, finish and critical finish machining parameters on the microstructural evolution of subsurface layers in Inconel 718. In order to assess the microstructural evolution in the subsurface layer following machining, advanced characterization methods including optodigital microscopy, X-ray diffraction and nanoindentation were used. Results showed that friction between the tool and the workpiece during machining lead to microstructural changes such as hardness enhancement on the surface, and softening on the subsurface. It was also observed that damage in the machined surface is related to the presence of defects such as cracks, cavities and carbide detachment from the surface. Finally, residual stress measurements revealed that, within the investigated parameters, the cutting speed has the most significant effect on surface integrity.
\end{abstract}

\section{INTRODUCTION}

Superalloys are used in the manufacturing of aerospace components such as turbine disks where high service temperatures are required $[1,2]$. Surface integrity of subsurface and surface layers resulting from machining is crucial for fatigue life improvement [3]. Yet, machining processes including hard turning affects surface integrity and induces microstructural alterations such as surface hardness enhancement resulting from work hardening, plastic deformation, microcracks, white layer formation, recrystallization and tensile thermal residual stresses [1, 4-8].

In order to achieve dimensional tolerance, manufacturing of aerospace components require a multi-step machining procedure which includes semi finishing, finishing and critical finishing.

This study intends to investigate the microstructural evolution of an Inconel 718 superalloy according to multi-step hard turning.

\section{EXPERIMENTAL INVESTIGATIONS}

Table 1 summarizes the machining parameters used during the different cutting steps: semi-finish, finish and critical finish. Using those parameters, 3D turning tests were carried out on a MAZAK center using age hardened cylindrical forged bars with a standard AMS heat treatment procedure. Machined specimens were sectioned, mounted and etched using an electrolytic solution containing $15 \mathrm{ml}$ and $30 \mathrm{ml}$ of $\mathrm{H}_{2} \mathrm{O}_{2}$ and $\mathrm{HCl}$ respectively in order to reveal grain boundaries and investigate the subsurface layers modifications. Grain size measurements were carried out using the MIP image analysis software (Nahamin Pardazan Asia, www.metsofts.com) as per ASTM 6 as shown in Fig. 1. The hardness was measured to be $38 \pm 1$ HRC. The chemical composition of Inconel 718 was determined through an EDAX technique and results are presented on Table 2 .

Table 1 Machining parameters

\begin{tabular}{lcccc}
\hline Machining step & $\begin{array}{c}\text { Cutting speed } \\
(\mathrm{m} / \mathrm{min})\end{array}$ & $\begin{array}{c}\text { Feed rate } \\
(\mathrm{mm} / \mathrm{rev})\end{array}$ & $\begin{array}{c}\text { Depth of cut } \\
(\mathrm{mm})\end{array}$ & Tool \\
\hline Semi-finish & 524 & 0.18 & 1.02 & Carbide \\
Finish & 590 & 0.08 & 0.25 & Carbide \\
Critical finish & 524 & 0.05 & 0.13 & Carbide \\
\hline
\end{tabular}


Table 2 Chemical composition of Inconel 718 (wt.\%)

\begin{tabular}{lccccc}
\hline \multicolumn{1}{c}{ Element } & wt.\% & $\begin{array}{c}\text { Standard } \\
\text { error }\end{array}$ & Element & wt.\% & $\begin{array}{c}\text { Standard } \\
\text { error }\end{array}$ \\
\hline $\mathrm{Ni}$ & 52.97 & 0.3 & $\mathrm{~V}$ & 0.09 & 0.01 \\
$\mathrm{Fe}$ & 18.51 & 0.15 & $\mathrm{Al}$ & 0.39 & 0.06 \\
$\mathrm{Cr}$ & 18.36 & 0.28 & $\mathrm{Ta}$ & 0.22 & 0.22 \\
$\mathrm{Nb}$ & 4.47 & 0.09 & $\mathrm{Si}$ & 0.22 & 0.22 \\
$\mathrm{Ti}$ & 1.02 & 0.03 & $\mathrm{C}$ & 0.07 & 0.01 \\
$\mathrm{Mo}$ & 3.14 & 0.41 & & & \\
\hline
\end{tabular}

An OLYMPUS DSX 500 opto-digital microscope and OLYMPUS LEXT OLS 4000 confocal microscope were used to assess the microstructure evolution during the various machining steps. Nanohardness measurements were carried out on the workpiece cross-section using a load of $1 \mathrm{mN}$ with a HYSITRON tribo-indenter and a Berkovich tip. The analysis of residual stress for machined surface was carried out using the $\sin ^{2} \psi$ method. The X-ray source was manganese K $\alpha$. Chromium was also used as filter with Bragg angle of $152.6^{\circ}$ in the crystallographic plane of fcc $\{311\}$. The measurements were performed at $\beta$ angles of $\pm 17.3, \pm 13.7, \pm 0.4$, and $0^{\circ}$. The applied oscillation was 2 degrees at each mentioned $\beta$ in order to improve the peaks intensities. X-ray elastic constant of 14478 $\mathrm{MPa}$ was taken into account for calculations.

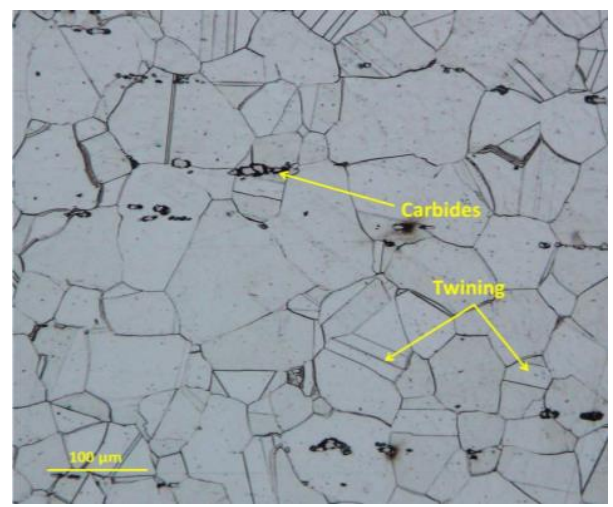

Fig. 1 Microstructure of Inconel 718 before machining

\section{RESULTS}

\section{Plastic deformation}

Fig. 2 (a), (b) and (c) reveals typical subsurface damage produced by hard turning. The force applied by the tool during machining deformed the grain according to the cutting direction. Grain and grain boundaries deformations are explained by the effect of the cutting force applied from the tool to the workpiece and of the high cutting temperatures induced during removing material. The obtained results (Table 3 ) reveal that the severity of plastic deformation in finish and critical finish is more than the one in the semi finish step. The extent of plastic deformation can be explained through the degree of grain boundaries distortion. Fig. 2 (b) and Fig. 2 (c) show that the grain boundaries are more deformed than the grain boundaries shown on Fig. 2 (a). This deformation leads to crack initiation at grain boundaries as shown on Fig. 3 (c). Published reports in the literature indicate that the structural alteration beneath the surface increased when cutting speed, depth of cut and tool wear are increased $[8,9]$.

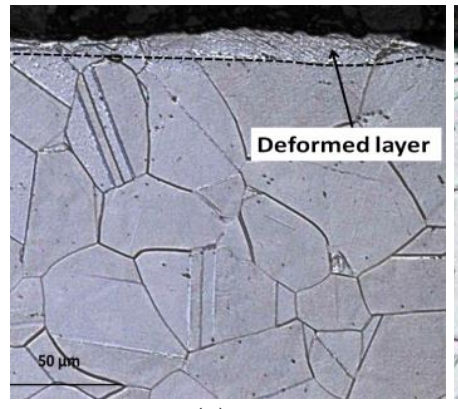

(a)

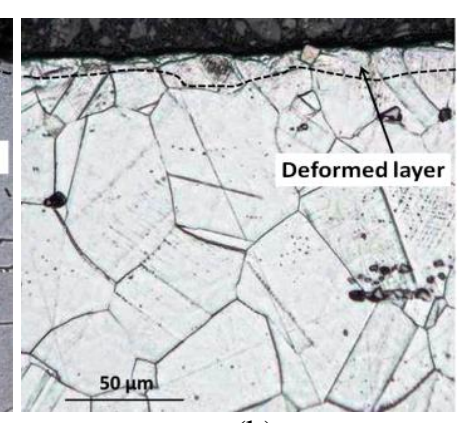

(b)

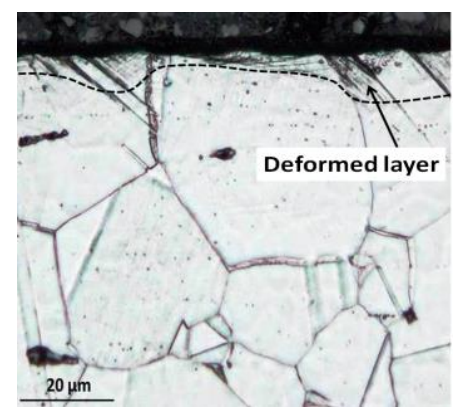

(c)

Fig. 2 Deformed layers after hard turning: (a) semi finish, (b) finish and (c) critical finish

In addition, Fig. 2 shows that the deformed zone is not uniform in the surface. The Table 3 summarizes the average minimum and maximum deformed zone thickness.

Table 3 Average deformed layers thickness after hard turning

\begin{tabular}{lccc}
\hline & Semi finish & Finish & Critical finish \\
\hline $\begin{array}{l}\text { Minimum average } \\
\text { thickness }(\mu \mathrm{m})\end{array}$ & $6.11 \pm 0.31$ & $5 \pm 0.3$ & $4.1 \pm 0.27$ \\
\hline $\begin{array}{l}\text { Maximum average } \\
\text { thickness }(\mu \mathrm{m})\end{array}$ & $10.03 \pm 0.21$ & $11.05 \pm 0.54$ & $8 \pm 0.135$ \\
\hline
\end{tabular}

\section{Defects in machined surface}

As depicted in Fig. 3 (a), (b) and (c) many types of surface discontinuities and defects such as gouge, brittle carbide zone, carbide detachment, cavities and microcracks. It can be seen that the degradation of surface quality of a stage to the next is very clear. Plucking of particles and carbides from the surface cause dragging and tearing defects in the next pass from the surface like microcracks in the critical finish. Moreover, each cutting step causes residual effects in the surface that will be affected by the next machining step. 


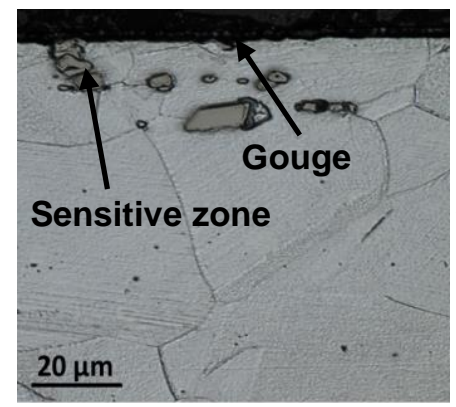

(a)

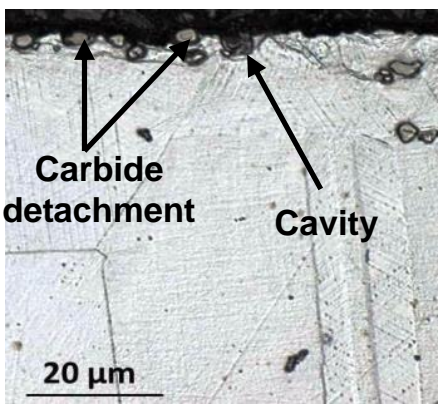

(b)

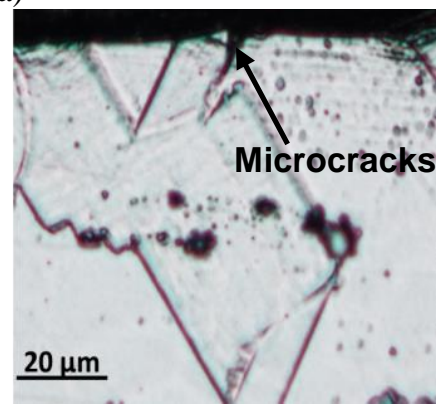

(c)

Fig. 3 Surface defects in hard turned layers of Inconel 718: (a) semi finish, (b) finish and (c) critical finish

\section{Nanohardness measurements}

In order to ensure the accuracy of nanohardness measurements of the subsurface layers, specific preparation was required for all samples. To this end, samples were cut along their longitudinal section resulting in a rectangular shape thereby increasing the accuracy and reliability of the hardness measurements. Standard polishing procedures according to ASTM E3-11 was used for the initial preparation of the samples [10]. In order to remove, or at least to minimize, the stresses induced during the polishing procedure all the samples were placed in an automatic vibromet polisher for twenty four hours. A matrix of $(10 * 6)$ indentations covering the area between the surface and bulk material was carried out using the following conditions: load of $1 \mathrm{mN}$ (indent size $2 \mu \mathrm{m}$ ), $5 \mathrm{~s}$ loading time, 5 $\mathrm{s}$ discharge time and $2 \mathrm{~s}$ break time. The spacing between each indent was kept at $6 \mu \mathrm{m}$ i.e. at least 3 times the size of the indent.

The hardness maps Fig. 4 (a), (b) and (c) illustrate a nonhomogenous distribution in the subsurface layer. Age hardened Inconel 718 contains $\gamma^{\prime}, \gamma^{\prime \prime}$ precipitates, primary and secondary carbides distributed over the entire surface [11]. The layers affected by hard turning are harder than the bulk material. The percentage of hardness increases compared to the average values of the bulk material are $4.5 \% 6.7 \%$ and $5.6 \%$ for semi finish, finish and critical finish, respectively. However, the subsurface layers appear to be softened as illustrated in Fig. 5.

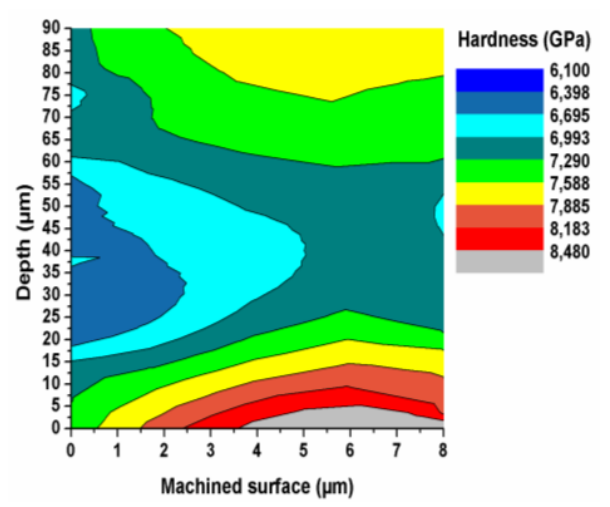

(a)

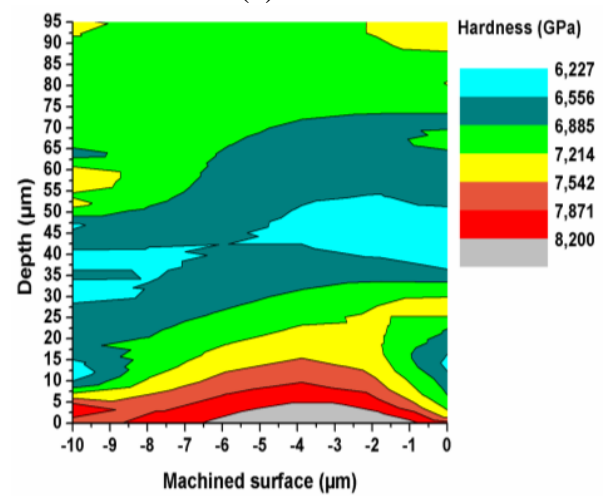

(b)

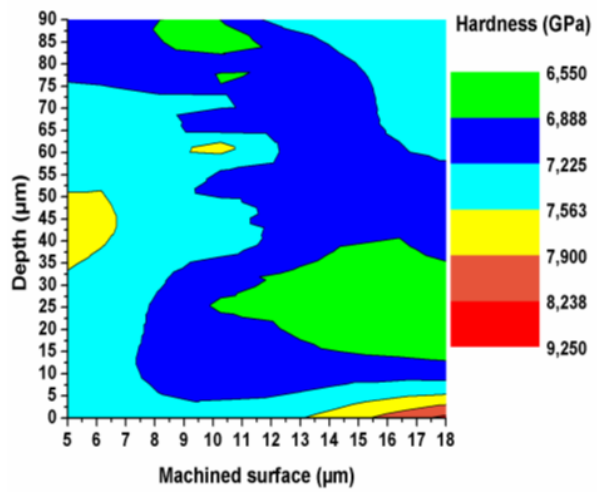

(c)

Fig. 4 Hardness maps in the hard turned surface and balk material: (a) semi finish, (b) finish and (c) critical finish

The low thermal conductivity of Inconel 718 is $11 \mathrm{~W} / \mathrm{mK}$ compared to steels $45 \mathrm{~W} / \mathrm{mK}$ and aluminum alloys $120 \mathrm{~W} / \mathrm{mK}$ $[12,13]$ increases the concentration of heat at the toolworkpiece interface. Ginting and Nouari [14] explained that the thermal softening effect on the subsurface layers is greater than the work-hardening effect on the surface, which is the reason for lower hardness values in the subsurface A similar behavior is observed in the present study as shown in Fig. 5. Just after the first 10 microns of the hardened layer, a thermal softening occurs. The softening is clearly demonstrated in the semi finish as well as the finish steps. The depth of the softened layer is in the range of $60 \mu \mathrm{m}$, while it is about $30 \mu \mathrm{m}$ for the critical 
finish step. It can be concluded that the thermal gradient generated in the first two mentioned steps is more than critical finish step. This result can be explained by the higher values of depth of cut $(1.02 \mathrm{~mm})$ and feed rate $(0.18 \mathrm{~mm} / \mathrm{rev})$ in the semi finish and the higher cutting speed $(590 \mathrm{~m} / \mathrm{min})$ in the finish step. According to the literature, the main source of temperature increase during machining is the cutting speed $[15,16]$.

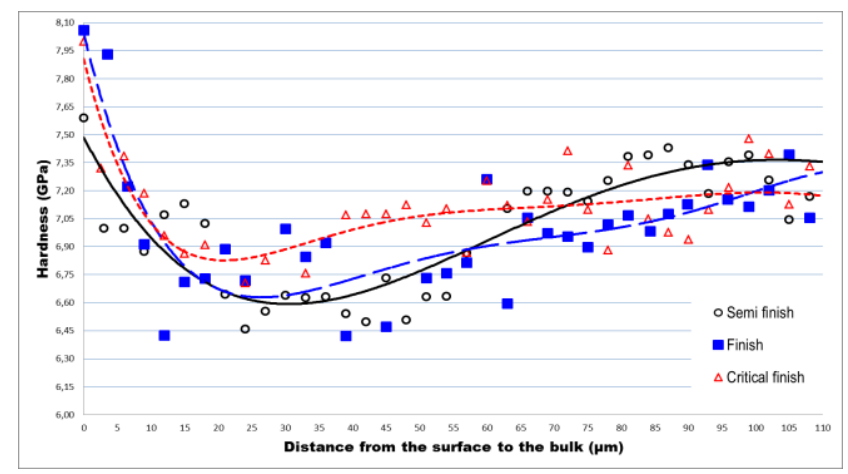

Fig. 5 Nanohardness depth profiles

\section{Surface residual stress}

Surface residual stress measurements were taken after each machining step in both the cutting and feeding directions as illustrated in Figs. 6 and 7. Results show that residual stresses are tensile in nature and are influenced by the cutting speed. Semi finish and critical finish steps showed that the intensity of the tensile residual stresses at the surface is almost identical. However, the variation of cutting speed from 524 to $590 \mathrm{~m} / \mathrm{min}$ increased the residual stress from 600 to $1200 \mathrm{MPa}$. Such high tensile residual stresses at the surface can be related to the substantial increase in the material hardness result from severe plastic deformation and work hardening during machining [6, 17].

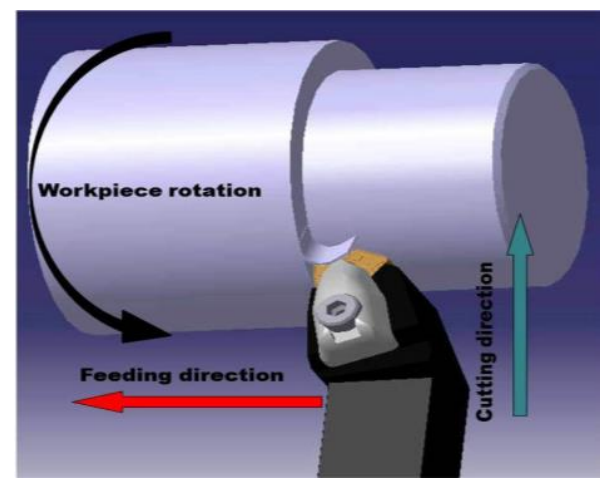

Fig. 6 Illustration of the cutting and feeding direction in turning

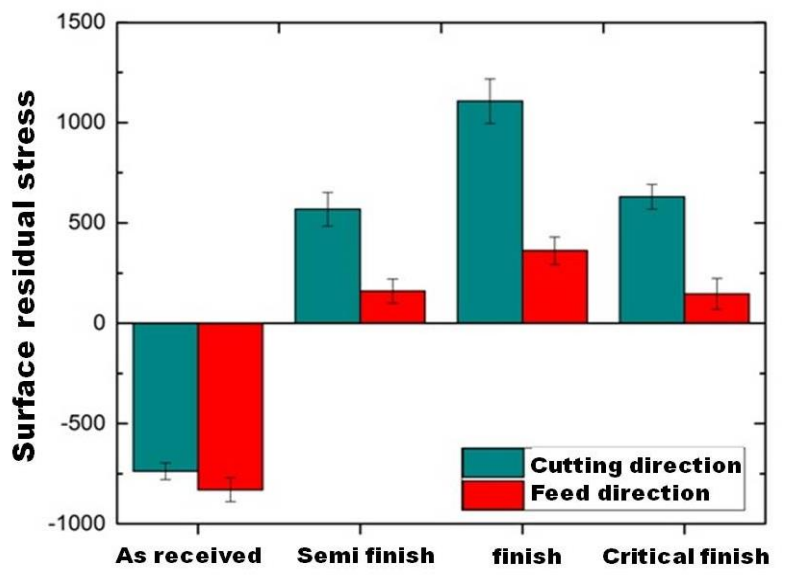

Fig. 7 Residual stress in the surface

\section{CONCLUSIONS}

In the presented work, an attempt was made to characterize the subsurface deformation and defects of Inconel 718 after hard turning using three different machining steps. Optical images, nanoindentation and XRD were used in order to quantify and detect the depth of deformation zone, defects and residual stress in the hard turned surfaces. The results indicated that many types and defects are present in the surface and subsurface layers such as: microcracks, cavities, softening in the subsurface layers and tensile residual stress. The work hardened layers in the three steps of machining semi finish, finish and critical finish does not exceed $11 \mu \mathrm{m}$.

\section{ACKNOWLEDGEMENTS}

This research has been conducted under CRIAQ MANU510 project. Support from the National Science and Engineering Research Council, NSERC is acknowledged as we as those from the industrial partners of the project: Pratt\&Withney Canada and Heroux-Devtek. The authors are thankful for the support provided Mr. John Gavita from Olympus Canada in optical and confocal microscopy examination and Professor Richard Chromik from McGill University for providing nanoindentation facility. The authors also appreciate the efforts of Jihane Ajaja for proofreading of the manuscript and Dr. Hossein Monajati for helping in residual stress measurements.

\section{REFERENCES}

[1] Ulutan, D. and T. Ozel, Machining induced surface integrity in titanium and nickel alloys: A review. International Journal of Machine Tools and Manufacture, 2011. 51(3): p. 250-280.

[2] A. Kortabarria, P.J. Arrazola, and K. Ostolaza, Multi Revolution Finite Element Model to Predict Machining Induced 
Residual Stresses in Inconel 718, in 14th CIRP Conference on Modeling of Machining Operations. 2013. p. 111-116.

[3] Novovic, D., et al., The effect of machined topography and integrity on fatigue life. International Journal of Machine Tools and Manufacture, 2004. 44(2-3): p. 125-134.

[4] Jawahir, I.S., et al., Surface integrity in material removal processes: Recent advances. CIRP Annals - Manufacturing Technology, 2011. 60(2): p. 603-626.

[5] He, A., et al., A comparative study on Johnson-Cook, modified Johnson-Cook and Arrhenius-type constitutive models to predict the high temperature flow stress in $20 \mathrm{CrMo}$ alloy steel. Materials \& Design, 2013. 52(0): p. 677-685.

[6] Pawade, R.S., S.S. Joshi, and P.K. Brahmankar, Effect of machining parameters and cutting edge geometry on surface integrity of high-speed turned Inconel 718. International Journal of Machine Tools and Manufacture, 2008. 48(1): p. 15-28.

[7] Bushlya, V., et al., Characterization of White Layer Generated when Turning Aged Inconel 718. Procedia Engineering, 2011. 19(0): p. 60-66.

[8] Zhou, J.M., et al., Effects of Tool Wear on Subsurface Deformation of Nickel-based Superalloy. Procedia Engineering, 2011. 19(0): p. 407-413.

[9] Tomita, Y., Development of fracture toughness of ultrahigh strength, medium carbon, low alloy steels for aerospace applications. International Materials Reviews, 2000. 45(1): p. 27-37.

[10] International, A., Standard Guide for Preparation of Metallographic Specimens. 2011.

[11] Chou, Y.K. and C.J. Evans, White layers and thermal modeling of hard turned surfaces. International Journal of Machine Tools and Manufacture, 1999. 39(12): p. 1863-1881.

[12] Bauccio , M., ASM Metals Reference Book. Third edition ed. 1993: ASM International, Materials Park.

[13] Metals Handbook, Properties and Selection: Irons, Steels, and High-Performance Alloys. 10 ed. Vol. 1. 1990: ASM International.
[14] Altenberger, I., et al., Cyclic deformation and near surface microstructures of shot peened or deep rolled austenitic stainless steel AISI 304. Materials Science and Engineering: A, 1999. 264(1-2): p. 1-16.

[15] Li, H.Y., et al., Application of artificial neural network and constitutive equations to describe the hot compressive behavior of 28CrMnMOV steel. Materials and design, 2012. 35: p. $557-$ 562.

[16] Shatla, M., C. Kerk, and T. Altan, Process modeling in machining. Part I: determination of flow stress data. International Journal of Machine Tools and Manufacture, 2001. 41(10): p. 1511-1534.

[17] Arunachalam, R.M., M.A. Mannan, and A.C. Spowage, Residual stress and surface roughness when facing age hardened Inconel 718 with $\mathrm{CBN}$ and ceramic cutting tools. International Journal of Machine Tools and Manufacture, 2004. 44(9): p. 879-887. 